\title{
Produção de vídeos e ensino da História
}

\author{
Henrique Luiz Pereira Oliveira*
}

\section{RESUMO}

O presente artigo propõe a análise de uma proposta metodológica para ensinar História através da produção de vídeos. Após um breve exame das práticas de produção de vídeos para os movimentos sociais no Brasil, são relatados experiências e impasses na realização de oficinas de vídeo para alunos de Graduação em História.

Palavras-chave: história e audiovisual, produção de vídeos e ensino, vídeo popular.

A apropriação da tecnologia do vídeo por grupos que ambicionavam formas autônomas de criação e comunicação engendrou experiências singulares. Diversos grupos engajados em atividades políticas, pedagógicas, culturais e artísticas vislumbraram a possibilidade de utilizar o vídeo para desenvolver processos de produção e exibição de audiovisuais independentes das coações do poder econômico, do Estado ou de outros mecanismos de dominação. Muitas vezes a intenção era justamente estabelecer um confronto com as estruturas de dominação. Neste sentido pode-se falar de uma conjunção histórica entre vídeo e utopia.

Vídeo e utopia

No Brasil a difusão do videocassete e das câmeras de vídeo ocorreu nos anos 80. Em um momento de grande efervescência política no país após o término da ditadura militar, diversas entidades (sindicatos, associações, ONGs etc.) passaram a utilizar o vídeo como um instrumento de ação política e pedagógica. Em 1984 foi

* Professor do Departamento de História da Universidade Federal de Santa Catarina e coordenador do Laboratório de Pesquisa em Imagem e Som-LAPIS. 
criada a Associação Brasileira de Vídeo Popular - ABVP - que passou a articular os realizadores de vídeos destinados aos movimentos sociais.

Grande parte das entidades que produziam vídeos populares possuía a sua própria estrutura de produção: câmeras de vídeo e equipamentos para montagem (ilha de edição). 0 custo de uma unidade de produção variava conforme o padrão de qualidade. Uma parcela dos realizadores de vídeos populares entendia que mais importante do que a qualidade do produto final era o processo, isto é, o desenvolvimento de uma experiência na qual a produção dos vídeos contribuísse para as comunidades refletirem sobre seus próprios problemas. A participaçã̃o da comunidade nas diversas etapas da produção dos vídeos era um ideal almejado por diversos realizadores.

Os produtores de vídeo popular no Brasil justificavam sua opção pelo vídeo em função de sua aplicabilidade à ação polííca: (1) o baixo custo do vídeo, que favorecia a democratização do acesso aos meios de produção; (2) a facilidade de circulação dos vídeos, que necessitava apenas de aparelhos de videocassete e poderia usufruir de uma rede de exibição junto aos movimentos sociais constituída por sindicados, associações de moradores, ONGS, escolas etc; (3) a agilidade da produç̧ão, que ao contrário do cinema não necessita esperar a revelação do material gravado, possibilitando que o registro de uma greve ou repressão policial fosse exibido logo após o acontecimento; (4) a facilidade na operação dos equipamentos, que favoreceria a democratização do processo de produção, pois permitia processos menos hierarquizados que o cinema, podendo inclusive assumir uma certa precariedade; (5) a possibilidade de fomentar uma efetiva participação popular, na medida em que os vídeos abordassem os movimentos populares fossem produzidos para os movimentos e envolvessem a sua participação nas etapas de realização. Devido a esses fatores, o vídeo seria um instrumento estratégico para a reversão do processo unidirecional e monopolista dos meios de comunicação de massa, conferindo voz ativa àqueles que antes seriam receptores passivos. (OLIVEIRA, 2001, p. 46).

A exibiç̃̃o dos vídeos populares era feita em locais que reuniam pessoas que compartilhavam de interesses em comum, como sindicatos, associações de moradores e grupos de minorias. Com o intuito de atingir um público mais amplo foram criadas as TVs de Rua, caracterizadas pela exibição dos vídeos em telões instalados em espaços abertos. Nos anos 90 a ABVP se mobilizou para romper o monopólio das redes de televisão, defendendo a criação de TT's populares. Foi desenvolvido um projeto para a equipar Centros de Comunicação Popular, que seriam instalados em 
cada uma das regiões do país, e para realizar oficinas de capacitação técnica para operar canais de TV de alcance local.

o monopólio das redes de TV que controlam as transmissões em canal aberto não foi quebrado, mas com a regulamentação das TVs a Cabo, em 1995, foram criados os canais de utilização gratuita: um canal comunitário, um canal educativo, um canal universitário e três canais legislativos. Os Canais Comunitários são de acesso público, abertos para a utilização livre por entidades não governamentais e sem fins lucrativos. (BRITTO, 1997, p. 14-15) Todavia a TV a Cabo é acessível apenas àqueles que podem pagar a assinatura mensal, excluindo justamente a parcela da população que mais poderia se beneficiar dos Canais Comunitários como estratégia de organização e luta.

Enquanto que no início dos anos 90 uma estrutura de produção de vídeos com razoável qualidade custava cerca de cem mil dólares, aiualmente uma unidade de produção satisfatória custa pouco mais de cinco mil reais. Uma câmera de vídeo digital mais simples custa em torno de três mil reais. Com o mesmo valor é possivel montar um computador para editar vídeos. Apesar da drástica redução dos custos de produção e da ampliação dos espaços para a veiculação, as utopias de utilização do vídeo na ação política estão em baixa. No entanto parece-nos bastante oportuno indagar de que maneira o ensino da história poderia se beneficiar da praticidade, da autonomia de produção e exibição e do baixo custo dos equipamentos de vídeo. Nesta perspectiva as experiências do movimento de vídeo popular são inspiradoras.

Vida Laboriada: uma experiência de produção de vídeo

Sem ter conhecimento das práticas de produção de vídeos para os movimentos sociais' ${ }^{1}$ em 1994, munidos de uma câmera que chegou na véspera da viagem, um grupo de professores e alunos do Curso de Graduação em História da Universidade Federal de Santa Catarina partiu para a cidade de Lajes, com o intuito de realizar um vídeo. A câmera foi operada por um aluno

I Em 1996 elaborei um projeto de Doutorado com o objetivo de estudar os vídeos de apoio ao ensino de Histórit. No decorrer das investigaçes tive conhecimento do movimento de vídeo popular no Brasil. Foi quando constatei as afinidades entre as propostas deste movimento e algumas de nossas concepções sobre o uso do vídeo. 
que lev o manual de instruçoses durante o translado. Contávamos com nosso entusiasmo e com a chaboração de um publicitário que cuidou da direção de folograba, orientando o operador da câmera a hazer enquadramentos menos convencionais, do modo a "esconder" os erros de gravacão.

Samos sem um roteiro, apenas com algumas idéias, decorrentes de pesquisa biblograficas e de uma visita preliminar à regiäo. Na medida em que os deponnentos ian sendo coletados as proprias questões que formulávamos eram alteratas. Ima parte das pessoas entrevistadas foi encontrada por acaso. As imagens e depoimentos foram coletados durante cinco dias, na semana que anteceden au Natal de 1994. Tendo em mäos onze horas de gravação, o grupo ficou dumte un ano analisando as imagens e os vinte e cinco depoimentos. Somente en agosto de 1996 o vídeo foi finalizado.

Antes las gravacóes tinhamos o propósito de abordar o êxodo rural e os processos de exchusa social na região. Em função do material coletado, parecia imposível seguir este intento. O que fazer com o material gravado? A soluçáo mais obvia era descrever cronologicamente a história economica da região pecuíria exploracio da aracária - apontando suas consequencia sociais. Enbova a sucesa a cronológica linear contribua para suprimir a arbitrariedade da narativa no docmentário tradicional, ela acaba muito mais servindo como recurso para velar as escolhas dos realizadores, para suprimir os múliplos possiveis dos acontecimentos e ocultar as incertezas sobre passado. Tal estratégia narativa nog outras possibildades, rechaca a complexidade de causas e exchi a sumera do discurso histónico (ROSENSTONE, 1997, p. 29). Acabamos por estrum a narrativa a partir da historia de vida de alguns trabalhadores, articulando os seus depoimentos com a formaça econômica da região.

A medida que o roteiro de edição anadurecia, a questão das escolhas tomava-se crucial. Muitas dúvidas remetiam a posura ética que deveriamos adotar Identilićvamo-nos com os "oprimidos" e pretendiamos evidenciar as formals de doninação, sem assumir um tom panfletário. Certos entrevistados foram repudiados pelos alunos que fizeram a seleção do material gravado, outros geraram simpatia. Desta forma alguns depoimentos foram censurados mais por critérios estéticos e afetivos do que por razões ideológicas ou histónicas.

A definição da forma também acarretava problemas. Optamos por suprimir a ligura do narrador clássico que detêm a compreensão da totalidade 
e explica os problemas, construindo a narrativa unicamente com a junção das falas dos entrevistados. Mas tais procedimentos de fragmentação e junção das falas construíram um discurso que não era o dos entrevistados, mas o nosso. Esta solução tinha implicações éticas que na época não soubemos contornar. Por outro lado, entendíamos que era ético evidenciar que o documentário era resultante de um certo modo de recortar e pensar a realidade, que a narrativa audiovisual era o resultado das escolhas derivadas de determinadas concepções, convicções, sentimentos, preconceitos etc. Portanto deveríamos explicitar a intervenção dos realizadores. Procuramos minimizar o tom realista do documentário utilizando efeitos em algumas imagens, de modo a enfatizar que se tratava de uma construção e não de um espelhamento do real. A distorção das imagens também visava compensar o fato de muitas tomadas terem sido gravadas com problemas (foco, balanço de cor, enquadramento, planos tremidos etc.).

Em função do público alvo, alunos do ensino fundamental e médio das escolas públicas, procuramos mostrar a dignidade do "caboclo" e evitar um caráter paternalista ou depreciativo. A primeira versão do vídeo terminava com depoimentos sobre o futuro, que the conferia um tom fortemente pessimista. Optou-se por alierar a montagem. Esta sequiência sobre o futuro foi antecipada e o vídeo foi concluído com os trabalhadores definindo o que é ser caboclo, enfatizando sua auto-afirmação através da apropriação do conceito de caboclo - que muitas vezes é utilizado pela elite local com um sentido pejorativo. Esta troca na ordem dos segmentos alterou totalmente o impacto emocional do vídeo.

Por razões políticas e operacionais o vídeo, que recebeu o título de "Vida Laboriada", não foi distribuído para as escolas do município de Lajes. Diferentemente do traço que marcou fortemente o vídeo popular, não garantimos o envolvimento dos indivíduos e das comunidades abordadas, nem na realização nem na exibição do vídeo. A distribuição dos vídeos e o acompanhamento da sua recepção são, aliás, etapas do processo que têm sido em geral bastante descuidadas, não só nas produções do LAPIS, mas em grande parte das produções independentes. 
Produção de vídeos e estudos históricos

Com base na experiência de produção do vídeo "Vida Laboriada", em 1996 o Departamento de História da UFSC passou a oferecer a disciplina Oficina de Vídeo-História, visando propiciar aos alunos de Graduação uma formação básica para a realização de vídeos de baixo custo. Com recursos do projeto "Oficinas de Vídeo-História: o ensino da História através da produção de audiovisuais", financiado pelo Programa de Apoio à Integração Graduaçãol Pós-Graduação/CAPES, foi criado o Laboratório de Pesquisa em Imagem e Som - LAPIS. Adquirimos una ilha de edição (S-VHS), uma câmera de vídeo e adaptamos um pequeno estúdio para gravação.

A primeira Oficina foi custeada pelo projeto, o que possibilitou a contratação de uma equipe de profissionais para ministrar as aulas e supervisionar a realização dos vídeos. Esta Oficina foi estruturada em quaro módulos: pesquisa, roteiro, gravação e edição. As pesquisas e roteiros tiveram por base dissertações desenvolvidas no Curso de Pós-Graduação em História da UFSC. Definiu-se a priori que os vídeos teriam no máximo cinco minutos e seriam realizados em grupos. Cinco roteiros foram elabonatos, mas apenas dois foran finalizados.

A implantação do LAPIS e das Oficinas de Vídeo-História foram, inegavelmente, frutos de una utopia pedagógica. As oficinas foram crialas com o objetivo de gerar um exercício com múltiplos desdobramentos: (a) entendíanos as oficinas como um espaço de treinamento para a criação de vídeos de apoio a ensino; (b) pretendia-se que através das escolnas envolvidas nas diversas etapas de realização dos vídeos, os alunos refletissem sobre a construtividade própria a conhecimento histórico; (c) acreditávanos que a realização dos vídeos, ao instrumentalizar os alunos para manipular e decodificar imagens e sons, capacitariam para a recepção crítica dos meios de comunicação e para a análise dos processos coletivos de modelação da subjetividade; (d) almejávamos que os vídeos produzidos promovessem debates nas escolas sobre a produção do conhecimento histórico e sobre as caracteristicas da narrativa audiovisual.

Nestas ambiçoes estava implícita a intença de superar alguns impasses dos audiovisuais de apoio ao ensino da história, em particular o descompasso 
entre as abordagens destes audiovisuais e as perspectivas abertas pela historiografia contemporânea. Ao mesmo tempo, com. relação aos procedimentos para a utilização de audiovisuais no ensino, presumíamos que além da análise do conteúdo, era fundamental avaliar com os alunos as características dos audiovisuais e as concepções de história que estes veiculam. Assim, a formação dos alunos para uma recepção crítica dos meios de comunicação poderia ser exercitada na própria análise dos audiovisuais de apoio ao ensino. Nesse sentido a utilização de audiovisuais no ensino deveria ser complementada com o estudo dos processos sociais de produção e circulação de imagens, procedimento estratégico para pensar os dispositivos contemporâneos que atuam na nossa própria constituição e na constituição daquilo que é configurado coletivamente como sendo a realidade.

Obviamente o conjunto de propostas que norteou a criação e execução das Oficinas de Vídeo-História era demasiado ambicioso. Para avaliar os avanços e impasses destas experiências é preciso separar três intenções: (a) ensinar história através da produção de vídeos; (b) capacitar alunos de história para produzir vídeos; (c) produzir vídeos de apoio ao ensino que contribuam para pensar o próprio processo de construção do conhecimento.

\section{a) Ensinar bisínria através da produção de vídeos.}

Refletir sobre a produção do conhecimento histórico através de experiências de produção de vídeos era a premissa fundamental do projeto. Até que ponto isto seria possível? Uma parte significativa das atividades das Oficinas era dedicada às análises de audiovisuais, enfatizando as relações entre a forma, a construção da narrativa e as concepções de história. Embora os audiovisuais escolhidos fossem bastante heterogêneos, distinguíamos dois pólos: os audiovisuais que pretendem expressar a verdade bisiórica, utilizando recursos para assegurar o realismo e veracidade da narrativa; e os audiovisuais que assumem o caráter problemático e interpretativo do conhecimento, seus aspectos contraditórios e provisórios, estimulando uma reflexão sobre os próprios procedimentos constitutivos da narrativa histórica e audiovisual. Mas dificuldades apareciam já no desenvolvimento das pesquisas. Os alunos que frequientavam as Oficinas provinham de diferentes fases do Curso de História, e mesmo de outros cursos. Esta exigência de reflexividade algumas vezes resultava em roteiros criativos, porém alicerçados em pesquisas frágeis. A clareza 
dos objetivos era preterida em função de experimentaçốes nem sempre consistentes. Todavia seria um contra-senso estimular abordagens mais tradicionais da história de modo a garantir produtos mais eficazes do ponto de vista da transmissão de conteúdos.

\section{b) Capacitar alunos de bistória para produzir videos.}

Qual deve ser o peso da formação técnica nas Oficinas? Quais os aspectos desta formação que devem ser privilegiados? Num primeiro momento as Oficinas foram oferecidas em um único semestre. Os alunos, divididos em equipes, escolhiam um teina, desenvolviam uma pesquisa, elaboravam um roteiro e participavam das etapas de gravação e edição dos vídeos. A maior parte do tempo era despendida na escolha de temas, na realização das pesquisas, na criação de roteiros e na análise de audiovisuais. Os alunos concebiam os vídeos mas não operavam os equipamentos.

No segundo semestre de 2002 as Oficinas passaram a ser divididas em dois semestres - o primeiro dedicado à pesquisa e roteiro e o segundo à gravação e edição. Passou-se a capacitar os alunos para operar os equipamentos. Cada grupo escolhia um aluno para participar de um mini-curso de câmera e outro para participar de um mini-curso de edição. Mesmo assim os objetivos mais elementares foram precariamente alcançados. A grande parte dos roteiros não foi realizada. No decorrer das onze Oficinas já ministradas, foram criados trinta e três roteiros, sendo que apenas dez vídeos foram concluídos. Mesmo assim o desenvolvimento das pesquisas e criação dos roteiros constituiu um momento de aprendizagem e reflexão.

As aulas iniciais das oficinas eram destinadas à escolha dos temas e à formação das equipes. Os temas não eram estabelecidos previamente nem era proposto que todo o grupo trabalhasse em um único projeto. 0 aspecto positivo era a motivação dos grupos em realizar vídeos com temas que escolheram. Mas os problemas eram diversos. De modo recorrente a escolha de temas ligava-se à preservação da cultura local, numa perspectiva folclorista. Era difícil orientar diversos vídeos e as tentativas de discutir coletivamente os roteiros resultavam em dispersão, pois cada grupo focava apenas no seu próprio projeto.

A organização do tempo é um grande desafio, pois as atividades de formação e as etapas de realização dos vídeos exigem que os alunos dediquem 
um tempo bem maior que as quatro aulas semanais previstas para a disciplina. O que deveria ser priorizado? A pesquisa? O desenvolvimento de roteiros? A análise de vídeos e as reflexões sobre concepções de história? A formação técnica? Na prática poucos alunos, apenas os que assumiram a realização do projeto, tiveram um aproveitamento efetivo. Com relação a grande maioria foi difícil avaliar o aproveitamento. Como ir além de aplaudir os poucos projetos que eram concluídos? Como analisá-los? Segundo quais critérios? Até que ponto o professor deve intervir na direção do processo (pesquisa e concepção de história, roteiro, gravação e edição)?

\section{c) Produzir videos que contribuam para pensar a construção do conbecimento.}

Além da formação para criação roteiros e para operar os equipamentos, a concepção e realização dos vídeos supõem um amplo repertório de conceitos, informações e reflexões sobre o audiovisual. Mas para a produção de um bom vídeo de apoio ao ensino da história não basta esta formação. Alias, se esta formação fosse suficiente seria melhor deixar esta produção com os profissionais do audiovisual. Há una questão que antecede o próprio roteiro: a pesquisa. Porém pesquisar não é só uma questão de coletar dados. Supõe um preparo que os alunos que chegam na Oficina não têm. Chegamos a cogitar que não cabia as Oficinas cuidar das pesquisas, que devíamos nos ater aos problemas específicos à realização dos vídeos. Claro que, mesmo com pesquisas deficientes, experiências interessantes foram realizadas, mas não alcançamos os principais objetivos das Oficinas: refletir sobre o conhecimento histórico através da produção de audiovisuais e produzir audiovisuais que favoreçam reflexões sobre a produção do conhecimento histórico. Com relação à produção de materiais de apoio ao ensino, além do repertório de dificuldades já mencionado, não precisamos com clareza o público alvo nem os objetivos a serem atingidos com os vídeos. Um aspecto positivo dos vídeos já realizados foi a experimentação de formatos: animação com bonecos de argila, animação através de sofiware gráfico, dramatização com atores e estruturas narrativas com multiplicidade de pontos de vista. São caminhos que podem ser explorados em fứuras produções. 
Wo segundo senertre de 2003 o LAPIS iniciou uma nova fase. Passamos a contar con trê ithas de edicão não lineares (edicão em computador) e com câneras digitais. Alóm de dois servidores técnico-administrativos (um operador de câmera e un editor) a equipe do LAPFS passou a integrar um grupo de alunos bolsistas e de volunirios que já haviam passado pelas oficinas e que aprenderam a operar as câmeras e os equipamentos de edição. Mas o fato mais significativo é que definimos um projeto de pesquisa para o LAPIS, o qual tem por objetivo a produção de uma série de vídeos abordando a produção cultural e as transformações urbanas em Florianópolis da segunda metade do século XX. Para dar suporte à pesquisa e à formação teórica constiúmos um grupo de estudos que se reúne semanalmente, composto por bolsistas, alunos en fase de elaboração de Trabalho de Conclusão de Curso, pós-graduandos e professores da UPSC e de outras instituiçóes. Visando facilitar a troca de informações foi criado um grupo de discussões na Internet e está sendo implantado um banco de dados.

Desta nova etapa resultam alguns aspectos decisivos. Na medida em que o Laboratório estabeleceu um projeto de pesquisa e conta com uma equipe apta a produzir vídeos e a apoiar as atividades das Oficinas, ficou mais fácil delimitar os objetivos. A produção de vídeos mais elaborados passa a ser atribuição da equipe do Laboratório. As próximas Oficinas priorizarão a formação para a produção de vídeos e as reflexões sobre o conhecimento histórico. Arravés das Oficinas novos alunos poderão se integrar às atividades do Laboratório, a começar pelos temas dos roteiros, que serão articulados ao projeto de pesquisa do LAPIS. A Oficina I terá como objetivo o trabalho com depoimentos: análise do uso de depoimentos em audiovisuais, formulação do projeto de pesquisa, definição de objetivos e cuidados na coleta dos depoimentos, formação técnica para operação da câmera e captação de áudio e análise do material gravado. A Oficina II, a partir do material já gravado, consistirá na criação dos roteiros e na edição dos vídeos. Espera-se, desta forma, envolver efetivamente os alunos nos problemas relativos à produção do conhecimento histórico e à sua socialização através de audiovisuais. 
Bibliografia

BRITTO, Bráulio e LIMA, Rafaela. Cartilha de acesso. Belo Horizonte, 1997.

OLIVEIRA, Henrique Luiz Pereira. Tecnologias audiovisuais e transformação social: o movimento de vídeo popular no Brasil (1984-1995). 2001. 487 p. Tese (Doutorado em História) Programa de Esíudos Pós-Graduados em História, Pontifícia Universidade Católica de São Paulo, São Paulo.

ROSENSTONE, Robert A. El pasado en imágenes: el desafío del cine a nuestra idea de la historia. Trad. Sergio Alegre. Barcelona, Editorial Ariel, 1997.

\section{Production of videos and History teaching}

\section{ABSTRACT}

The present article proposes methodologies to teach History through the production of videos. After a brief exam of the video production practices to the social movements in Brazil, experiences and impasses are observed in the accomplishment of video shops to History Graduation students.

Key words: history and audiovisual, production of videos and teaching, social video. 